\title{
Assessment of Radiative Forcing by Light-Absorbing Particles in Snow from In Situ Observations with Radiative Transfer Modeling
}

\author{
S. MCKenZIE SKILES \\ Department of Geography, University of Utah, Salt Lake City, Utah \\ THOMAS H. PAINTER \\ Jet Propulsion Laboratory, California Institute of Technology, Pasadena, California
}

(Manuscript received 18 April 2018, in final form 16 July 2018)

\begin{abstract}
It is well established that episodic deposition of dust on mountain snow reduces snow albedo and impacts snow hydrology in the western United States, particularly in the Colorado Rockies, which are headwaters for the Colorado River. Until recently the snow observations needed to physically quantify radiative forcing (RF) by dust on snow were lacking, and analysis of impacts used a semiempirical relationship between snow optical properties and observed surface reflectance. Here, we present a physically based daily time series of RF by dust and black carbon (BC) in snow at Senator Beck Basin Study Area, Colorado. Over the 2013 ablation season (March-May), a snow-aerosol radiative transfer model was forced with near daily measured snow property inputs (density, effective grain size, and dust/BC concentrations) and validated with coincidentally measured spectral albedo. Over the measurement period, instantaneous RF by dust and $\mathrm{BC}$ in snow ranged from 0.25 to $525 \mathrm{~W} \mathrm{~m}^{-2}$, with daily averages ranging from 0 to $347 \mathrm{~W} \mathrm{~m}^{-2}$. Dust dominated particulate mass, accounting for more than $90 \%$ of RF. The semiempirical RF values, which constitute the continuous longterm record, compared well to the physically based RF values; over the full time series, daily reported semiempirical RF values were $8 \mathrm{~W} \mathrm{~m}^{-2}$ higher on average, with a root-mean-square difference of $16 \mathrm{~W} \mathrm{~m}{ }^{-2}$.
\end{abstract}

\section{Introduction}

Mountain snowmelt runoff dominates surface water hydrology in the western United States, and timing and rates of snow depletion exert controls on ecology, biogeochemistry, and climate. A growing body of literature has established the important role of aerosol deposition on snow in the headwaters of the Colorado River, an essential waterway that provides water to seven western U.S. states and Mexico. Radiative forcing (RF), the enhanced surface absorption due to surface darkening, by dust deposition in the Colorado Rocky Mountains has been shown to advance melt by $1-2$ months, shift timing and magnitude of peak runoff, and reduce total water yield (Deems et al. 2013; Painter et al. 2010, 2007b; Skiles and Painter 2016, 2017; Skiles et al. 2012, 2015). Furthermore, the intensity of snowmelt runoff from the southern Colorado Rockies exhibits a linear relationship with dust on snow RF but not with air temperature

Corresponding author: S. McKenzie Skiles, m.skiles@geog.utah. edu
(Painter et al. 2018), and research indicates that dust $\mathrm{RF}$ is a major factor contributing to operational river runoff forecast errors in the Colorado River basin (CRB; Bryant et al. 2013).

The presence of light-absorbing particles (LAP) in snow has been well documented at a number of sites across North America (Adolph et al. 2017; Delaney et al. 2015; Doherty et al. 2014, 2016). Although concentrations are not always high enough to impact melt, snow darkening by LAP has been shown to have relevant radiative impacts in the mountain snow cover in the Sierra Nevada (Hadley et al. 2010; Sterle et al. 2013) and Pacific Northwest (Kaspari et al. 2015), and in other snowcovered areas globally, including Europe (Matt et al. 2018; Tuzet et al. 2017), High Mountain Asia (Kaspari et al. 2014; Matt and Burkhart 2018), and northern China (Zhao et al. 2014). These are just examples of the many emerging studies that are focused on constraining the impacts of LAP in snow and ice in terms of hydrology and climate, and we refer interested readers to a recent review of the topic for a more thorough discussion (Qian et al. 2015). Remote sensing and modeling 
efforts indicate that the most intense radiative forcing by LAP in snow, in the western United States, is that from episodic dust deposition in the southern Colorado Rockies (Oaida et al. 2015; Painter et al. 2012a).

Dust is very effective at forcing melt in the Colorado Rockies because the majority of dust events occur in the spring corresponding to the initiation of snowmelt due to increasing solar radiation. Additionally, dust is not entrained in meltwater, such that individual dust layers combine at the surface and compound albedo decay as snowmelt progresses (Skiles and Painter 2017). The primary source of dust that is deposited on snow in the Colorado Rockies is the southern Colorado Plateau (Skiles et al. 2015), and evidence suggests that frequent and intense dust deposition is a relatively new process since settlement and disturbance of the West (Neff et al. 2008). Additionally, dust emission is projected to intensify with climate warming (Munson et al. 2011). Therefore, it is important to constrain the radiative impacts of dust and other LAP on snow and apply that understanding to improve modeled snowmelt runoff timing and magnitude in this region.

Although the hydrologic impacts of dust on snow have been monitored for over a decade in the Colorado Rockies, measurements were not carried out in a way to facilitate physically based modeling of radiative forcing by LAP. Specifically, measurements of spectral snow albedo and effective snow grain size were not made at regular intervals previously, and the optical properties of deposited dust, which vary widely by region, had never been characterized. Additionally, concentrations of black carbon (BC), the product of incomplete combustion and another aerosol widely recognized to impact snow albedo (Bond et al. 2013), had never been analyzed in combination with dust concentrations with the aim of assessing their unique and combined radiative impacts. To address this data gap, a high temporal, spectral, and vertical resolution snow property dataset was collected at Swamp Angel Study Plot (SASP), Senator Beck Basin Study Area (SBBSA), San Juan Mountains, Colorado, during the 2013 ablation season (from peak snow water equivalent to snow depletion; Skiles and Painter 2017). Neardaily variability in snow density, effective grain size, and dust and $\mathrm{BC}$ content was determined from this time series, and the impact to surface albedo investigated. The regionally specific optical properties of deposited LAP were determined from hemispherical reflectance and particle size distributions using a novel inversion technique (Skiles et al. 2017).

We use these measurements in combination with a snow and aerosol radiative transfer model, updated with the site specific dust optical properties, to determine spectral and spectrally integrated radiative forcing by dust and $\mathrm{BC}$ in snow. Unique radiative transfer model runs for dust and $\mathrm{BC}$, separately and in combination, were used to partition the radiative contribution from each constituent and determine total instantaneous and daily radiative forcing for each day measurements were made in the field. This physically based dataset offers a unique opportunity to validate in situ and remote sensing radiative forcing products. Additionally, the physically based radiative forcing time series was compared to the continuous semiempirical radiative forcing time series estimated from changes in surface reflectance following the method presented in Painter et al. (2007b), which constitutes the long-term record of dust radiative forcing in the Colorado Rockies (Painter et al. 2007b).

\section{Methods}

\section{a. Forcing and validation measurements}

Following is a brief description of the relevant snow observations for radiative transfer model forcing and validation; a detailed description of the full dataset can be found in Skiles and Painter (2017). Snow observation and sampling took place at SASP $\left(37.906914^{\circ} \mathrm{N}\right.$, $\left.107.711322^{\circ} \mathrm{W} ; 3368 \mathrm{~m}\right)$, SBBSA, San Juan Mountains, Colorado (Fig. 1). The SBBSA was established in 2003 to study the hydrologic impacts of dust on snow, and two instrumentation towers have been collecting snow energy balance measurements continuously since water year 2005, supplemented regularly by snow profile and dust event observations (Landry et al. 2014; Painter et al. 2012b). Measurements at the instrumentation towers include standard atmospheric variables (air temperature, wind speed and direction, relative humidity) and snow depth, as well as net radiation flux measurements: net solar from a set of uplooking and downlooking pyranometers and net longwave derived from an uplooking pyrgeometer and a downlooking snow temperature sensor. Snow observation and sampling began on 1 March, albedo and snow effective grain size measurements began on 25 March, and all measurements continued until snow depletion on 18 May. There were 40 total days of radiative transfer observations that captured peak snow water equivalent and the transition from relatively clean to dust-laden snow. Relative to the full SBBSA record, water year 2013 was a dry year, with the lowest peak snow depth $(1.78 \mathrm{~m})$, and was also the dustiest in terms of total deposited mass $\left(>50 \mathrm{~g} \mathrm{~m}^{-2}\right.$; Skiles and Painter 2017).

Near-daily observations included spectral snow albedo, stratigraphy of snow density, snow temperature, effective snow grain size, and collections of snow samples for laboratory analysis of dust and black carbon. Daily observations began with snow albedo, which was 


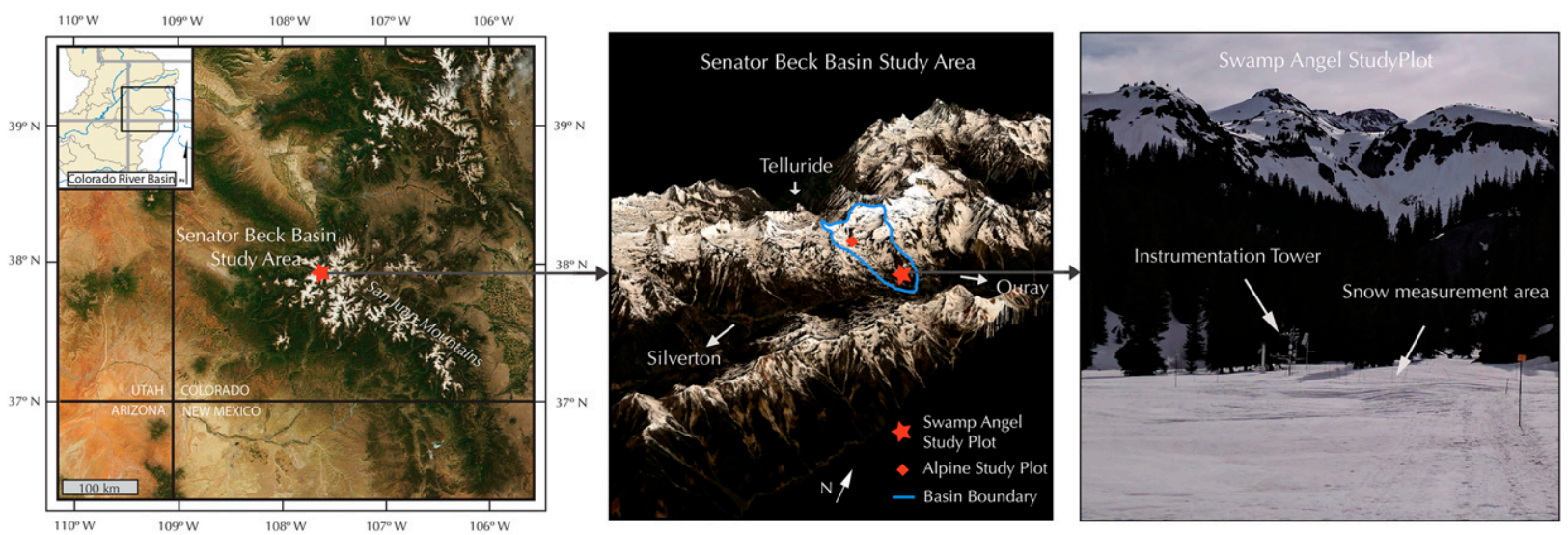

FIG. 1. Nested site overview of study location from the regional to local scale. The location of the instrumentation tower and adjacent snow measurement area, where the observations of snow physical and optical properties presented here took place, are labeled.

measured directly above the snow sample site with a field spectrometer (ASD FieldSpec3; 350-2500 $\mu \mathrm{m}$ across 2151 bands) coupled with a remote cosine receptor foreoptic, by taking the convolution of 10 uplooking and 10 downlooking measurements. Next, a snow pit was excavated and the snow pit face smoothed for sampling of effective snow grain size every $2 \mathrm{~cm}$ via contact spectroscopy (Painter et al. 2007a), snow temperature every $10 \mathrm{~cm}$, and snow density every $10 \mathrm{~cm}$ using a $1-\mathrm{L}$ snow density cutter. Then a set of 10 snow samples was collected every $3 \mathrm{~cm}$ across the top $30 \mathrm{~cm}$ of the snow using a gravimetrics board to maintain sample volume $(25 \mathrm{~cm} \times$ $25 \mathrm{~cm} \times 3 \mathrm{~cm})$. Snow samples were stored in WhirlPak sample bags and kept frozen until time of analysis. Snow pits were backfilled each day, and the following day snow excavation would take place a meter behind the previous pit face to sample undisturbed snow (Skiles and Painter 2017).

Snow samples were analyzed in the Snow Optics Laboratory at NASA's Jet Propulsion Laboratory. Prior to analysis, snow samples were removed from the freezer and allowed to melt in a refrigerator before placing them in an ultrasonic bath to agitate settled particles. Then total sample mass was recorded before drawing off a $50 \mathrm{~mL}$ subsample for black carbon analysis. The remainder of the sample was reweighed and then vacuum filtered through a preweighed $0.495-\mu \mathrm{m}$ filter. After filtered particles were fully dry, they were reweighed to return dust mass $(\mathrm{g})$, loading $\left(\mathrm{g} \mathrm{m}^{-2}\right)$, and concentration $\left(\mathrm{mgg}^{-1}\right.$ or ppt by weight). Black carbon content in subsamples was analyzed with a single particle soot photometer (SP2; Droplet Measurement Technologies) coupled to an ultrasonic nebulizer (Cetac) to aerosolize the melted snow. Briefly, the instrument measures black carbon in individual aerosol particles and concentrations $\left(\mathrm{ng} \mathrm{g}^{-1}\right.$ or $\mathrm{ppb}$ ) are reconstructed from air and water flows following the methods of Wendl et al. (2014). The laboratory analysis methodology is described in more detail in Skiles and Painter (2017) and Skiles et al. (2017).

\section{b. Radiative transfer model}

In the absence of LAP, which predominantly impact snow albedo in the visible wavelengths, snow albedo is controlled by snow effective grain size and ice absorption in the near-infrared wavelengths (Warren 1982). Therefore, direct RF by LAP can be calculated by taking the difference in absorption between a "dirty" snow albedo and a theoretical clean snow albedo for the same grain size. For this study, clean and particulatecontaining snow albedo were simulated with the offline version of the Snow, Ice, and Aerosol Radiation (SNICAR) model (Flanner and Zender 2005, 2006), which has been used to study RF by LAP in snow from the point (Kaspari et al. 2014, 2015) to regional scale (Flanner et al. 2007, 2009).

The model computes multiple scattering and reflectance from snow and aerosol mixtures across 470 bands $(0.3-5.0 \mu \mathrm{m})$ at $10-\mathrm{nm}$ resolution with a single-layer version of the two-stream, multilayer radiative approximation of Toon et al. (1989). Snow property inputs, which can be specified in multiple layers, include snow effective grain size, snow density, and concentrations of LAP. Other inputs include ground/substrate albedo and the solar zenith angle. The single scattering optical properties for ice are extracted from lookup tables, which are included for a large range of grain sizes (between $10 \mu \mathrm{m}$ and $5 \mathrm{~mm}$ at $1-\mu \mathrm{m}$ resolution) and have been updated to reflect the revised ice optical property compilation of Warren and Brandt (2008). Lookup tables are provided for several aerosol types including two types of BC (sulfate coated/uncoated), dust in four 
April 26th, 2013
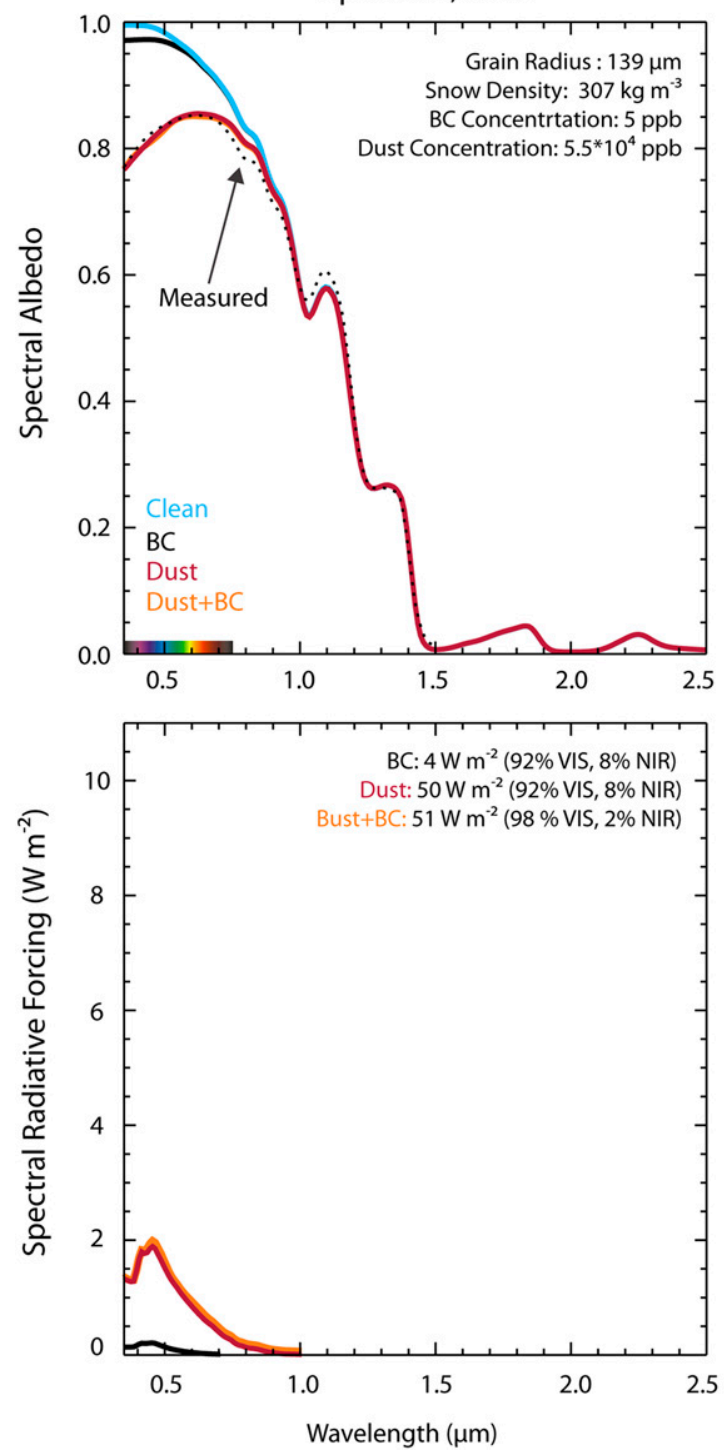

May 2nd, 2013
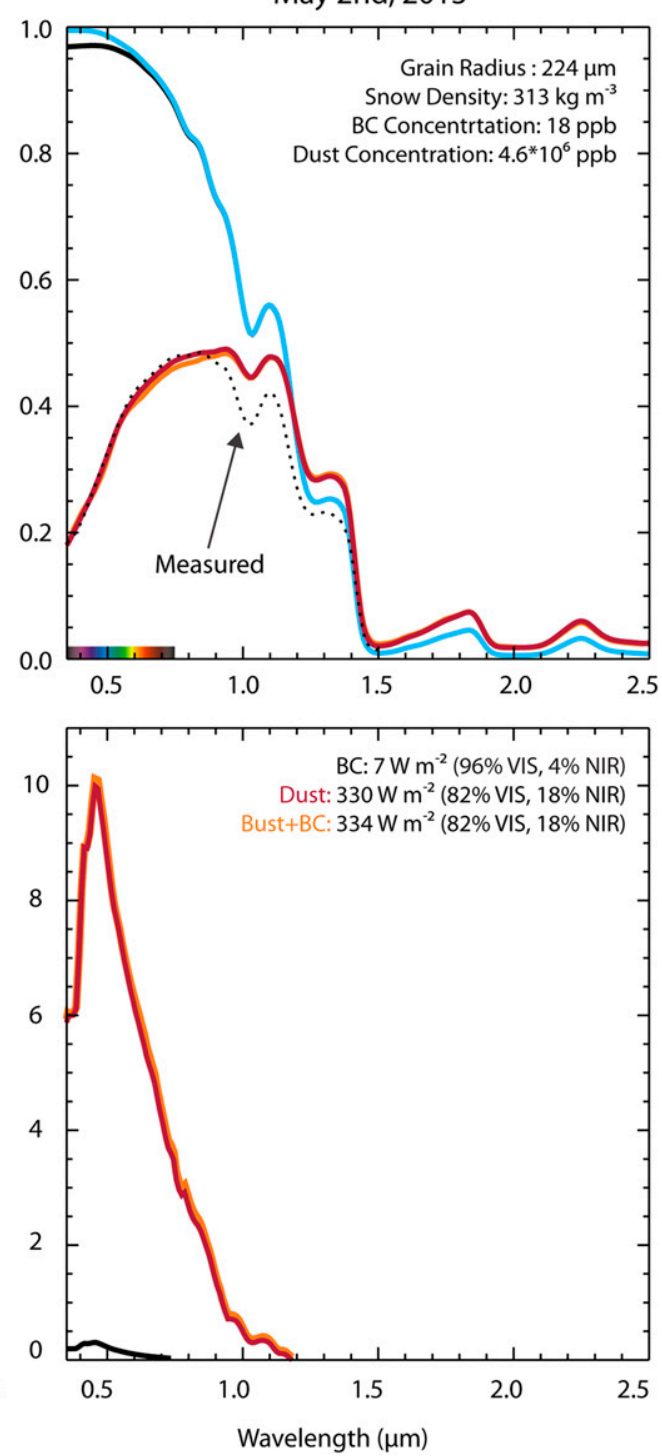

FIG. 2. (top) Spectral albedo for two days with moderate and high surface dust concentrations. SNICAR inputs are indicated for each day, and measured spectral albedo is shown with a dashed line. (bottom) The corresponding spectral RF, the difference in absorption between clean and LAP containing snow.

size bins, and volcanic ash. We updated the model to include both a location specific solar irradiance spectrum and dust optical property lookup table, as described below.

\section{c. Measurement inputs}

Albedo was modeled with SNICAR for each day on which coincident snow sampling and spectroscopy were completed in the field (Fig. 2). Snow property inputs were specified in 11 total layers; in the "active" upper 10 layers, spanning the top $30 \mathrm{~cm}$ in $3-\mathrm{cm}$ increments, density and LAP concentrations were layer-specific following gravimetric sampling, and effective grain size values were resampled from 2- to $3-\mathrm{cm}$ resolution. In the lowest layer, which represents the bulk snowpack, density and grain size inputs represent daily average values below the top $30 \mathrm{~cm}$, and dust/BC concentrations remain constant to reflect concentrations sampled across the lower snowpack profile (1-L samples in $10-\mathrm{cm}$ increments, from beneath the top $30 \mathrm{~cm}$ to the ground) in the first snow pit.

Albedo was modeled for four scenarios: clean snow (no dust or BC), snow with dust only, snow with BC only, and snow with dust and BC. Measured densities 
and grain sizes remain the same in each scenario, and therefore RF in this context represents the direct impact of LAPs (enhanced surface absorption due to surface darkening) and does not capture the indirect impact of enhanced grain growth (Painter et al. 2007b). Daily changes in albedo and RF were estimated by running the model hourly to account for changes in snow reflectance with sun angle by varying the solar zenith angle. Daily average values reported here represent average values across daylight hours because, by definition, RF would be $0 \mathrm{~W} \mathrm{~m}^{-2}$ at night because there is no incoming solar irradiance; 24 -h averages would be approximately half of the daily average values reported here.

In SNICAR, BC was specified as the uncoated variety, the optical properties of which have a mass absorption cross section of $7.5 \mathrm{~m}^{2} \mathrm{~g}^{-1}$ at $550 \mathrm{~nm}$, corresponding to the value suggested by Bond and Bergstrom (2006) (Flanner et al. 2007). Dust concentrations were specified in a new dust category incorporated into SNICAR to reflect the optical properties of dust deposited in snow in the Colorado Rockies (Skiles et al. 2017). Briefly, the single-scattering optical properties required for radiative transfer calculations were inverted from measured dust reflectance and particle size distribution. Multiple scattering and reflectance were modeled with DISORT (Stamnes et al. 1988) from single-scattering properties, which were modeled with Mie theory, for the measured grain size distribution and a specified value for the real part of the complex refractive index $(n=$ 1.525; Grams et al. 1974). This representation more accurately captures absorption by dust in this region and reduces errors in albedo modeling by $>50 \%$ relative to the more general dust characterization provided with SNICAR.

\section{d. Albedo and radiative forcing}

Snow reflectance varies spectrally, and therefore estimating the spectrally integrated albedo and RF $\left(\mathrm{W} \mathrm{m}^{-2}\right)$ requires the spectral distribution of incoming solar radiation. Because field spectrometer measurements were not collected in irradiance mode, and irradiance measurements at the SBBSA instrumentation towers are not spectrally resolved, clear sky spectral irradiance was modeled hourly between 0.35 and $2.5 \mu \mathrm{m}$ at $10-\mathrm{nm}$ resolution with the Santa Barbara DISORT Atmospheric Radiative Transfer model (SBDART; Ricchiazzi et al. 1998). To account for daily variation in actual sky conditions, the modeled spectral irradiance was scaled such that the summation equaled broadband irradiance measured at the instrumentation tower. We recognize that this approach captures total irradiance but does not account for the shift in spectral irradiance that occurs with cloud cover.
From SNICAR albedo and SBDART irradiance spectrally weighted albedo between 0.35 and $2.5 \mu \mathrm{m}$ [broadband (BB)], between 0.35 and $0.75 \mu \mathrm{m}$ [visible (VIS)], and between 0.75 and $2.5 \mu \mathrm{m}$ [near/shortwave infrared (NIR)] was calculated by dividing the summation of the product of irradiance and albedo by the summation of irradiance, that is, for broadband albedo:

$$
\alpha=\frac{\sum_{\lambda=0.35 \mu \mathrm{m}}^{2.5 \mu \mathrm{m}} I \times \alpha_{\text {lap }} \Delta \lambda}{\sum_{\lambda=0.35 \mu \mathrm{m}}^{2.5 \mu \mathrm{m}} I \Delta \lambda},
$$

where $I$ is scaled spectral irradiance at the given solar zenith angle, $\alpha_{\text {lap }}$ is the modeled albedo with dust and/or BC at the same solar zenith angle, and $\lambda$ is the wavelength $(\mu \mathrm{m})$.

Radiative forcing was estimated by taking the summation of the product of spectral irradiance and the difference between the spectrally weighted dust/BC albedo and clean snow albedo, which represents the enhanced surface absorption due to dust/BC, again for broadband wavelengths:

$$
\mathrm{RF}=\sum_{\lambda=0.35 \mu \mathrm{m}}^{2.5 \mu \mathrm{m}} I \times(\Delta \alpha) \Delta \lambda,
$$

where $\Delta \alpha=\alpha_{C}-\alpha_{\text {lap }}$, which is the difference between clean and LAP-laden snow albedo at the same hour, for the same snow grain size and density.

\section{e. Model performance}

To validate SNICAR we compared modeled albedo for the dust and BC scenario, which represents observed snow conditions, to coincident spectral and spectrally integrated albedo from the field spectrometer and to broadband albedo from pyranometers mounted on the adjacent SASP instrumentation tower (see Fig. 1). Prior to the comparison, the higher spectral resolution field spectrometer measurements were resampled to SNICAR wavelengths. The difference between modeled and measured values is quantified in terms of 1) difference in albedo and 2) difference in reflected solar radiation $\left(\Delta\right.$ flux; $\mathrm{W} \mathrm{m}^{-2}$ ).

\section{f. Radiative forcing comparison}

Physically based radiative forcings modeled following the methods described above are compared to the existing in situ dust RF record at SASP, which is estimated indirectly from surface reflectance following the method first presented by Painter et al. (2007b). This method calculates RF for two scenarios: the minimum case, which accounts for albedo reduction in the visible wavelengths due to surface darkening (the direct 
impact) and the maximum case, which additionally accounts for expansion of RF into the NIR and enhanced grain growth [first indirect impact (i1)]. This is done by partitioning the proportion of the change in NIR/SWIR albedo due to the presence of dust versus grain coarsening for relatively clean snow, a relationship that was developed at SBBSA (Painter et al. 2007b). Reported radiative forcings are then the average of these two scenarios.

The minimum radiative forcing $F_{d \min }$ case is

$$
F_{d \min }=E_{\text {vis }} \Delta_{\text {vis }},
$$

where $E_{\text {vis }}$ is visible irradiance $\left(\mathrm{W} \mathrm{m}^{-2}\right)$ and $\Delta_{\text {vis }}=0.92-\alpha_{\text {vis }}$, with $\alpha_{\text {vis }}$ being measured visible albedo and 0.92 being the mean visible albedo for relatively dust-free snow at SBBSA (Painter et al. 2007b).

The maximum radiative forcing $F_{d \max +\mathrm{i} 1}$ is

$$
F_{d \max +\mathrm{i} 1}=0.5\left\{E_{\mathrm{vis}} \Delta_{\mathrm{vis}}+E_{\text {nir }} \alpha_{\text {nir }}[(1 / \xi)-1]\right\},
$$

where if

$$
\Delta_{\text {vis }} \leq 0.17, \text { then } \xi=1-1.689 \Delta_{\text {vis }},
$$

else if

$$
\Delta_{\text {vis }}>0.17, \text { then } \xi=0.67,
$$

and $E_{\text {nir }}$ is the NIR/SWIR net shortwave flux and $\alpha_{\text {nir }}$ is the NIR/SWIR albedo.

Spring radiative forcings are reconstructed at the end of each water year from 15 March (Painter et al. 2007b; Skiles et al. 2012, 2015). The record is continuous, not discrete, as it is based solely on instrumentation and requires no snow sampling.

\section{Results and discussion}

\section{a. Modeled albedo}

Examples of modeled and measured spectral albedo are shown in Fig. 2, and daily average (BB, VIS, and NIR) albedos for all scenarios are shown in Fig. 3. Daily broadband albedo for modeled clean snow $\left(\alpha_{C}\right)$ ranged from 0.82 to 0.74 . In the absence of LAP ice absorption dominates albedo, and therefore NIR $\alpha_{C}$ exhibited a greater range $\left(0.66-0.5 ; 23 \%\right.$ difference) than VIS $\alpha_{C}$ (0.98-0.97; $2 \%$ difference). Although there were periodic increases in $\alpha_{C}$ due to new snowfall, the trend was decreasing over the measurement period corresponding to increasing grain size with snow metamorphism (Fig. 3). Because of the low BC concentrations sampled in WY13 (1-26 ppb), daily snow albedo in the presence of BC only $\left(\alpha_{\mathrm{BC}}\right)$ exhibited a similar range to $\alpha_{C}$. Although changes in VIS $\alpha_{\mathrm{BC}}$ over the measurement period were slightly greater than that of VIS $\alpha_{C}$, indicating a minor enhancement of absorption by $\mathrm{BC}$, the relationship between $\mathrm{BC}$ concentrations, grain size, and albedo indicate that declines in $\alpha_{\mathrm{BC}}$ over the record were also mainly controlled by grain growth/snow metamorphism.

Albedo in the presence of dust and $\mathrm{BC}\left(\alpha_{D+\mathrm{BC}}\right)$ ranged from 0.80 to 0.30 . Reduction in $\alpha_{D+\mathrm{BC}}$ over the measurement period was mainly controlled by dust concentration, with $\alpha_{D+\mathrm{BC}}$ decreasing linearly with exponential increases in surface dust concentrations. Although the majority of absorption by dust occurs in the VIS, it expands to the NIR with increasing dust concentrations (Fig. 2). Across this dataset the relationship between $\alpha_{D+\mathrm{BC}}$ and grain size was not significant, which we attribute to the heavy dust loading dominating snow albedo decay, similar to the relationship between dust concentrations and measured albedo presented in Skiles and Painter (2017). Albedo in the presence of dust only $\left(\alpha_{D}\right)$ is similar to $\alpha_{D+\mathrm{BC}}$, ranging from 0.81 to 0.32 .

\section{b. Model performance and uncertainty}

Broadband snow albedo is consistently overestimated by $2 \%-3 \%$ by SNICAR (for the $\alpha_{D+\mathrm{BC}}$ scenario) relative to measured broadband albedo at the instrumentation tower. The largest differences in albedo occurred between 27 April and 2 May, when dust layers combined at the surface and albedo rapidly reduced. When this time period is excluded, the difference between $\alpha_{D+\mathrm{BC}}$ and measured albedo reduces to $+1 \%$. The difference in reflected radiation ( $\Delta$ flux) between measured and modeled albedo was as great as $\pm 150 \mathrm{~W} \mathrm{~m}^{-2}$ at the hourly time scale, but over the full measurement period the average $\Delta$ flux was $-19 \mathrm{~W} \mathrm{~m}^{-2}$, a $5 \%$ overestimation of reflected flux for the $\alpha_{D+\mathrm{BC}}$ scenario.

Difference between measured and modeled spectral albedo for 14 days across the measurements period is discussed in detail in Skiles et al. (2017). Briefly, snow albedo is best matched in the visible wavelengths, to within $2 \%$ on average, with an average $\Delta$ flux of $-7 \mathrm{Wm}^{-2}$. Spectral albedo was most poorly matched in NIR in the presence of heavy dust loading, with differences as great as $25 \%$ and corresponding $\Delta$ flux of $-30 \mathrm{~W} \mathrm{~m}^{-2}$. On average, the NIR difference was $9 \%$ and $\Delta$ flux was $-13 \mathrm{~W} \mathrm{~m}^{-2}$; the lower solar irradiance in these wavelengths results in a $\Delta$ flux that does not scale proportionally with the percent difference between the VIS and NIR. Across the full range of snow reflectance, the $\Delta$ flux was $-20 \mathrm{~W} \mathrm{~m}^{-2}$, a $5 \%$ difference from measurements. This is similar to the $\Delta$ flux for the hourly broadband comparison at the instrumentation tower, and this spectral analysis was completed for dust only; when $\mathrm{BC}$ was included $\left(\alpha_{D+\mathrm{BC}}\right)$ spectral albedo modeling is improved by $1 \mathrm{~W} \mathrm{~m}^{-2}$ over the full range of snow reflectance. 

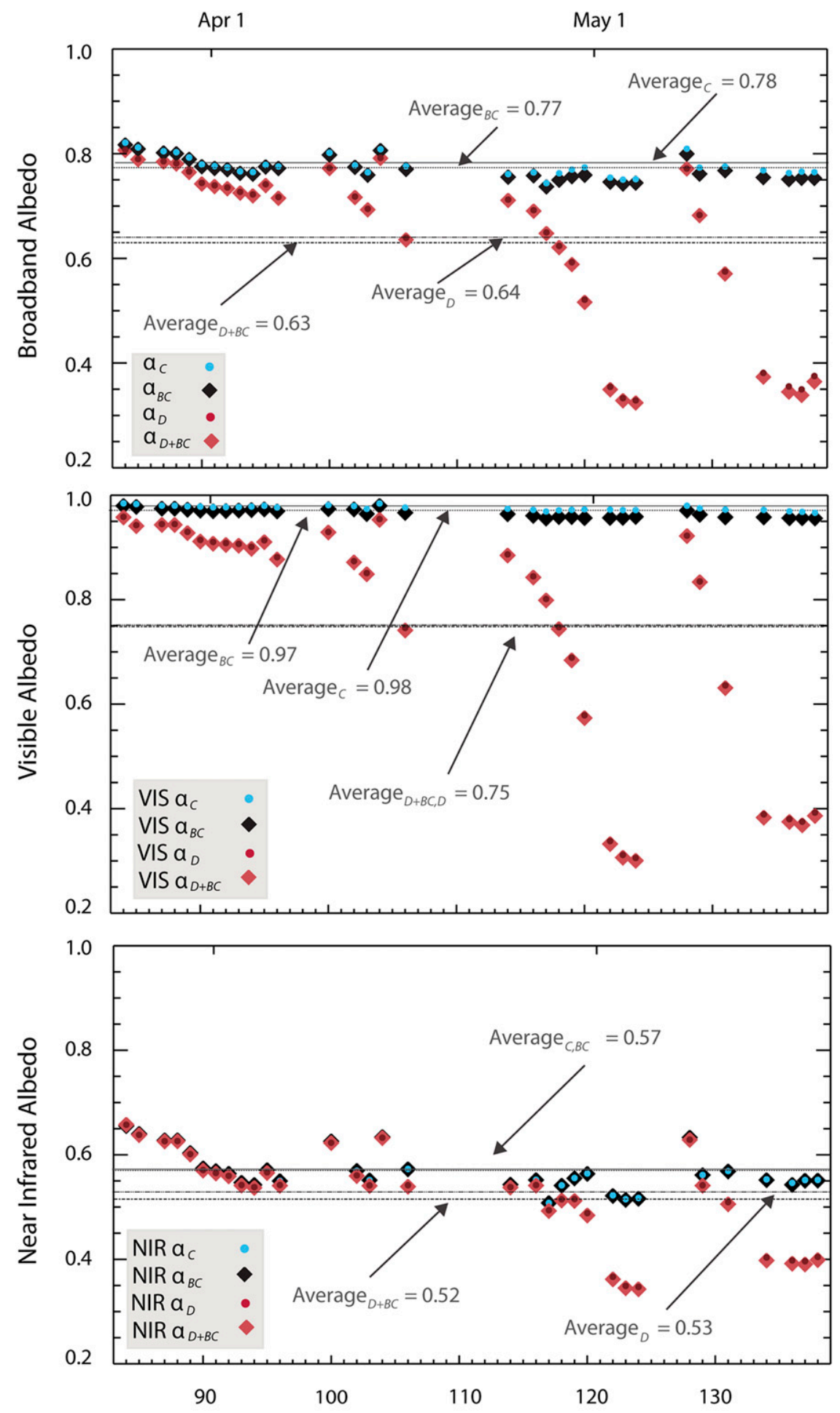

Day of Year 2013

FIG. 3. Daily average (top) BB, (middle) VIS, and (bottom) NIR albedo modeled with SNICAR for clean snow $\left(\alpha_{C}\right)$, snow containing only BC $\left(\alpha_{\mathrm{BC}}\right)$, snow containing only dust $\left(\alpha_{D}\right)$, and snow containing dust and $\mathrm{BC}\left(\alpha_{D+\mathrm{BC}}\right)$ over the measurement record. Gray lines show record average albedo for each scenario. 
There are a number of sources of uncertainty in the modeled albedo values presented here. First, there are uncertainties in the snow and aerosol forcing variables; for example, uncertainty in snow effective grain retrieved by contact spectroscopy is $\pm 10-50 \mu \mathrm{m}$ for grain sizes between 50 and $900 \mu \mathrm{m}$ (Nolin and Dozier 2000) and the method has a sensitivity of $\pm 20 \mu \mathrm{m}$ for measurements collected by a trained observer (Skiles and Painter 2017). Uncertainties in black carbon concentrations analyzed with an SP2 can be greater than $60 \%$ (Kaspari et al. 2014; Schwarz et al. 2012; Wendl et al. 2014), and the sensitivity of the method in the presence of dust can be as high as 15\% (Skiles and Painter 2017). Second, there are uncertainties in aerosol and snow optical properties associated with reducing model complexity; for example, snow grains and aerosols are nonspherical but are treated as spheres in SNICAR, an imperfect but reasonable assumption for albedo modeling, where nonspherical errors average out when integrating over reflectance and illumination angles. There is also uncertainty related to internal and external aerosol mixing in snow; SNICAR treats aerosols only as external mixtures that may account for errors in the NIR/SWIR at high dust concentrations [see the top-right panel of Fig. 2 and discussion in Skiles et al. (2017)]. Additionally, SNICAR uses representative (i.e., generic) optical properties for aerosols, which in reality are variable and can be altered by atmospheric transport. For BC concentrations reported here, changing the black carbon type (uncoated versus sulfate coated) results in a maximum albedo uncertainty of $0.4 \%$, whereas Skiles et al. (2017) found that default dust optical properties resulted in albedo errors of $50 \%-70 \%$, motivating the use of regionally specific optical properties in this study. There are other aerosol in snow radiative transfer models available that address some of these uncertainties, like the spherical assumption (Libois et al. 2013), but all have their limitations (Tuzet et al. 2017).

It is important to recognize these sources of uncertainty, but it is their cumulative impact that is most relevant to this study. The albedo comparison results indicate that the measured spectral and broadband albedo are consistent with each other, and that relative to measured albedo there is a small, but consistent, bias in the SNICAR modeled albedo. This bias is relevant for RF because it propagates through as an underestimation of the additional absorbed solar radiation by LAP, indicating the values we report below are conservative estimates of RF.

\section{c. Radiative forcing}

\section{1) DusT + BC}

Intraseasonal variation and general trends in radiative forcing by dust $+\mathrm{BC}\left(\mathrm{RF}_{D+\mathrm{BC}}\right)$ are determined by dust events, new snowfall, and snowmelt rates, which control LAP concentrations in the surface and near-surface layers (Skiles et al. 2012). In the first two weeks of the measurement period (from 25 March to 8 April) when dust concentrations in the surface layers were low, from $7.9 \times 10^{-4}$ to $6.0 \times 10^{-2}$ parts per thousand by weight (pptw), daily average $\mathrm{RF}_{D+\mathrm{BC}}$ (hereafter, simply $\mathrm{RF}_{D+\mathrm{BC}}$ ) ranged from 10 to $39 \mathrm{~W} \mathrm{~m}^{-2}$ (Fig. 4). In the following week (8-16 April) $\mathrm{RF}_{D+\mathrm{BC}}$ was similar, $38 \mathrm{~W} \mathrm{~m}^{-2}$, despite dust events 6-8 (D6-8) depositing $98 \%$ of the season total dust mass. A large increase in $\mathrm{RF}_{D+\mathrm{BC}}$ did not immediately accompany the dust deposition events because a series of snowfall events kept dust content in the upper layers low. A period of high pressure at the end of April, characterized by clear skies and no precipitation, resulted in snowmelt that led to the emergence, and then convergence, of the D6-8 individual dust layers. As this process took place $\mathrm{RF}_{D+\mathrm{BC}}$ increased from $39 \mathrm{~W} \mathrm{~m}^{-2}$ on 26 April to $146 \mathrm{~W} \mathrm{~m}^{-2}$ on 30 April, when D8 first emerged and D9 was deposited.

The highest $\mathrm{RF}_{D+\mathrm{BC}}$ values occurred between 2 and 4 May, when the surface dust concentrations were the highest ( $>5.0 \mathrm{pptw})$. Instantaneous values over this time period peaked between 400 and $500 \mathrm{~W} \mathrm{~m}^{-2}$. Daily average $\mathrm{RF}_{D+\mathrm{BC}}$ peaked on 3 May, corresponding to the highest sampled dust concentration $\left(341 \mathrm{~W} \mathrm{~m}^{-2}\right.$; 5.9 pptw dust). The total absorption by the snowpack, over $70 \%$ of incoming solar radiation, over this time period resulted in rapid melt and scavenging of both mass from snow grains and dust concentrations (Skiles and Painter 2016), leading to a decrease in $\mathrm{RF}_{D+\mathrm{BC}}$ to $270 \mathrm{~W} \mathrm{~m}^{-2}$ on 4 May. Dust was buried by snowfall on 8 May, briefly reducing $\mathrm{RF}_{D+\mathrm{BC}}$ to $<100 \mathrm{~W} \mathrm{~m}^{-2}$. The dust quickly resurfaced, accompanied by a rise in radiative forcing to $221 \mathrm{~W} \mathrm{~m}^{-2}$ on 14 May and then $281 \mathrm{~W} \mathrm{~m}^{-2}$ on 17 May. On the final day of sampling, $\mathrm{RF}_{D+\mathrm{BC}}$ decreased to $158 \mathrm{~W} \mathrm{~m}^{-2}$, which is again attributed to lower dust concentrations due to scavenging of dust from the surface layers, and lower irradiance.

The portion of RF that occurred in the NIR expanded with increasing dust concentrations (see Fig. 2), and because clean scenario and LAP scenario runs utilized the same grain size input, this is mainly determined by the wavelength range over which there is a divergence between clean/LAP albedo curves $\left(\lambda \alpha_{C}-\lambda \alpha_{D+\mathrm{BC}}>0\right)$. The wavelength at which the two spectral curves separate, referred to as the wavelength of divergence, increases from $0.7 \mu \mathrm{m}$ for relatively clean snow at the beginning of the measurement period to $1.2 \mu \mathrm{m}$ when D6-9 was present as a merged layer at the surface. Correspondingly, the NIR contribution to radiative forcing increased from $5 \%$ to $20 \%$ with an increase in dust concentration from 0.1 to $>4.0$ pptw. This is relevant 

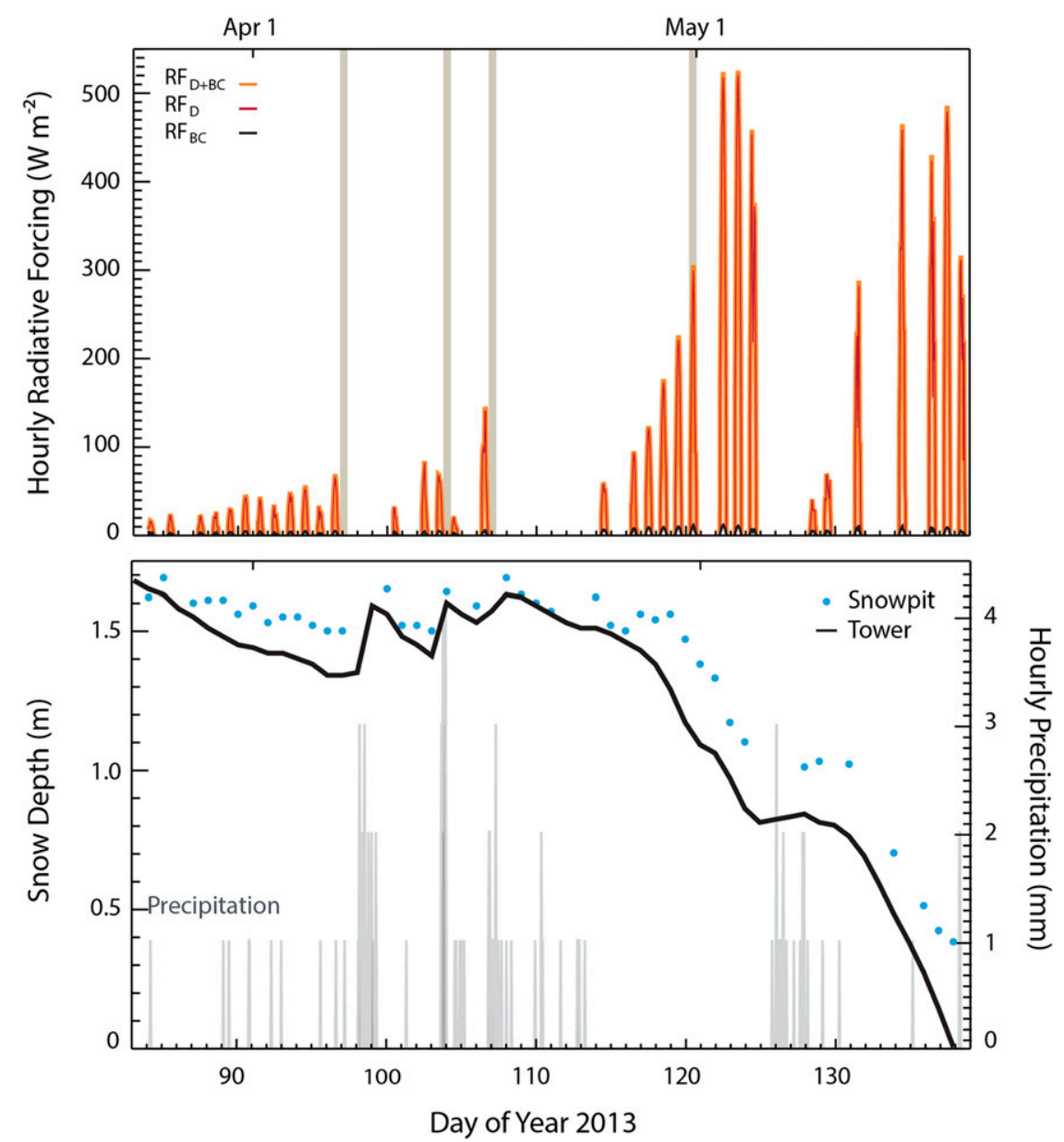

FIG. 4. Hourly RF for dust, BC, and dust plus BC calculated with SNICAR, with dust event timing (beige lines), precipitation, and snow depth (from the snow pit and automatic snow depth sensor at the instrumentation tower) over the measurement period. Note that $\mathrm{RF}_{\mathrm{BC}}$ varies on the scale of $0-10 \mathrm{~W} \mathrm{~m}^{-2}$, whereas $\mathrm{RF}_{D}$ and $\mathrm{RF}_{D+\mathrm{BC}}$ vary on the scale of $0-500 \mathrm{~W} \mathrm{~m}^{-2}$ and overlay each other. Gaps in the record indicate days when RF could not be calculated due to missing dust and $\mathrm{BC}$ concentrations, and not necessarily zero RF.

because the relationship between dust concentrations and the wavelength of divergence could be used to invert for dust concentrations in the absence of snow sampling.

\section{2) Dust/BC ONLY}

There was a minor reduction in RF between daily average $\mathrm{RF}_{D+\mathrm{BC}}$ and dust-only $\left(\mathrm{RF}_{D}\right)$ scenarios: $2 \mathrm{Wm}^{-2}$ on average over the measurement period. The same patterns were exhibited: the lowest $\mathrm{RF}_{D}$ values occurred in the beginning of the measurement period and on days with new snowfall $\left(9-37 \mathrm{~W} \mathrm{~m}^{-2}\right)$, increased with snowmelt as dust came to the surface $\left(40-143 \mathrm{~W} \mathrm{~m}^{-2}\right)$, and peaked with D6-9 present as a merged layer at the surface $\left(337 \mathrm{~W} \mathrm{~m}^{-2}\right.$ peak, $257 \mathrm{~W} \mathrm{~m}^{-2}$ average). Again, similar to $\mathrm{RF}_{D+\mathrm{BC}}$, the NIR contribution to RF increased with rising dust concentrations, from $\sim 4 \%$ in the beginning of the measurement period to $\sim 18 \%$ when dust is at the surface.

Daily average radiative forcing by $\mathrm{BC}$ only $\left(\mathrm{RF}_{\mathrm{BC}}\right)$ was $3.5 \mathrm{~W} \mathrm{~m}^{-2}$ on average and was between $85 \%$ and $98 \%$ ( $92 \%$ average) less than that by $\mathrm{RF}_{D}$. Patterns are similar to those exhibited by $\mathrm{RF}_{D}$ because $\mathrm{BC}$ concentrations covaried with dust concentrations. The lowest $\mathrm{RF}_{\mathrm{BC}}$ occurred prior to $\mathrm{D} 6\left(1.5-2.8 \mathrm{~W} \mathrm{~m}^{-2}\right)$, increased over the time period that dust layer D6-8 deposited/emerged $\left(3.1-4.8 \mathrm{~W} \mathrm{~m}^{-2}\right)$, and were highest when there is high dust content at the surface ( $7 \mathrm{~W} \mathrm{~m}^{-2}$ peak, $5 \mathrm{~W} \mathrm{~m}^{-2}$ average). The NIR contribution never increased above $10 \%$, with absorption past $0.75 \mu \mathrm{m}$ accounting for $0 \%-8 \%$ of absorption ( $4 \%$ on average). 


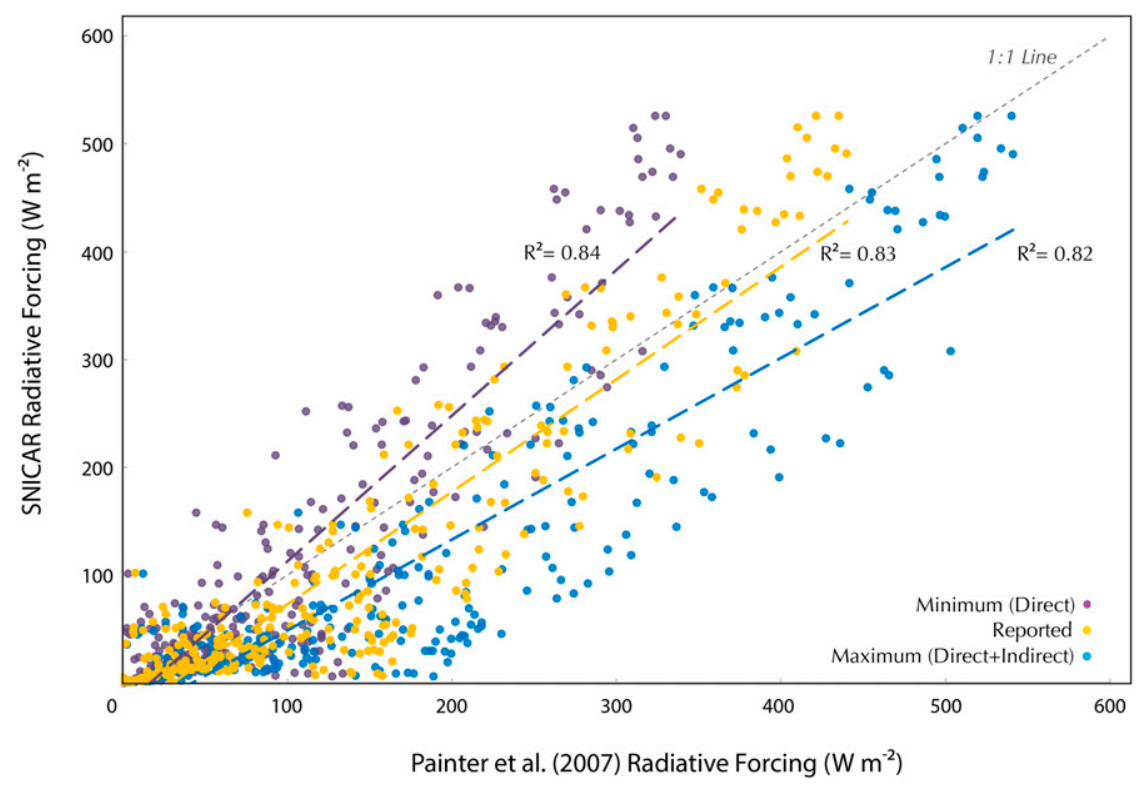

FIG. 5. Scatterplot for RF calculated $\left(\mathrm{RF}_{D+\mathrm{BC}}\right)$ from snow measurements using SNICAR to those calculated by the Painter method with linear best fit lines and $R^{2}$ values. The $1: 1$ line is shown in gray. Radiative forcing by SNICAR represents direct RF only, the Painter method includes a calculation for minimum (direct only) and maximum RF (direct + indirect) and the reported value is the average between these two.

The difference between $\mathrm{RF}_{D}$ and $\mathrm{RF}_{D+\mathrm{BC}}$ is the radiative impact of $\mathrm{BC}$ in the presence of dust. This difference, between 0.2 and $4.5 \mathrm{~W} \mathrm{~m}^{-2}$, increased as $\mathrm{RF}$ increased, but the percent difference, between $1 \%$ and $5 \%$, decreased as RF increased. Therefore, the proportion of RF accounted for by $\mathrm{BC}$ decreased with increasing dust concentrations. On average, the $\mathrm{RF}$ contribution by $\mathrm{BC}$ was $1.6 \mathrm{~W} \mathrm{~m}^{-2}$ less in the presence of dust relative to $\mathrm{RF}_{\mathrm{BC}}$ alone, a $50 \%$ reduction. This result, reduced absorption efficacy, is consistent with another study that uses SNICAR to investigate the impacts of dust and $\mathrm{BC}$ in a region of heavy dust loading in the Himalaya (Kaspari et al. 2014). Although BC in SNICAR is 30 times more absorbing than the dust deposited in snow in the Rocky Mountains (Skiles et al. 2017), BC was a minute fraction of total impurity concentration (from $0.0002 \%$ to $0.1 \%, 0.01 \%$ on average) and in the presence of such heavy dust loading even a highly absorptive material such as $\mathrm{BC}$ was relatively insignificant.

\section{d. Radiative forcing comparison}

Daily mean RF estimated via the Painter et al. (2007b) $\left(\mathrm{RF}_{\mathrm{P} 07}\right)$ ranges from 0 to $302 \mathrm{~W} \mathrm{~m}^{-2}$ over the measurement period, with instantaneous values ranging from 0 to $440 \mathrm{~W} \mathrm{~m}^{-2}$ (Fig. 5). These reported values represent the average of the minimum (direct impact; $\mathrm{RF}_{\operatorname{minP07}}$ ) and maximum (direct + first indirect impacts; $\mathrm{RF}_{\operatorname{maxP} 07}$ ) radiative forcing scenarios. The average difference between $\mathrm{RF}_{\operatorname{maxP} 07}$ and $\mathrm{RF}_{\operatorname{minP07}}$, the portion of $\mathrm{RF}$ that would be attributed to the indirect effect of enhanced grain growth, was $24 \mathrm{~W} \mathrm{~m}^{-2}$. This difference was lowest over periods of frequent snowfall (7-20 April; $8 \mathrm{~W} \mathrm{~m}^{-2}$ ) and highest when dust was at the surface (1-5 May and 12-17 May; $53 \mathrm{~W} \mathrm{~m}^{-2}$ ).

Because radiative forcing estimated here with radiative transfer modeling accounts for only the direct effect, we would expect it to be less than $\mathrm{RF}_{\mathrm{P} 07}$ and comparable to $\mathrm{RF}_{\operatorname{minP07}}$, and up until 29 April $\mathrm{RF}_{D+\mathrm{BC}}$ was consistently lower than $\mathrm{RF}_{\mathrm{P} 07}$. The average difference was $15 \mathrm{~W} \mathrm{~m}^{-2}$ when snow was relatively clean prior to heavy dust deposition (from 25 March to 6 April) and was lower, $4 \mathrm{~W} \mathrm{~m}^{-2}$, when dust was present in the nearsurface layers (10-29 April). During emergence/ convergence of dust at the surface (from 30 April to 4 May), hourly $\mathrm{RF}_{D+\mathrm{BC}}$ increased above $\mathrm{RF}_{\mathrm{P} 07}$, by $22 \mathrm{Wm}^{-2}$ on average, but still fell below $\mathrm{RF}_{\text {maxP07. }}$ Over the remainder of May, $\mathrm{RF}_{D+\mathrm{BC}}$ was slightly elevated above $\mathrm{RF}_{\mathrm{P} 07}$; on average it was $7 \mathrm{Wm}^{-2}$ higher but remained below $\mathrm{RF}_{\operatorname{maxP07}}$ by $32 \mathrm{Wm}^{-2}$. Averaged over the full measurement period daily $\mathrm{RF}_{D+\mathrm{BC}}$ was $5 \mathrm{Wm}^{-2}$ greater than $\mathrm{RF}_{\operatorname{minP} 07}, 8 \mathrm{Wm}^{-2}$ less than $\mathrm{RF}_{\mathrm{P} 07}$, and $23 \mathrm{Wm}^{-2}$ less than $\mathrm{RF}_{\max \mathrm{P} 07}$. The root-mean-square difference was lowest for $\mathrm{RF}_{\mathrm{P} 07}$ at $16 \mathrm{Wm}^{-2}$ and was $20 \mathrm{Wm}^{-2}$ and $27 \mathrm{~W} \mathrm{~m}^{-2}$ for $\mathrm{RF}_{\min \mathrm{P07}}$ and $\mathrm{RF}_{\operatorname{maxP} 07}$, respectively.

These results show that the reported RF values from the Painter method have a slight positive bias for cleaner 
snow and slight negative bias for dust-laden snow. The minimum (direct) semiempirical RF values have the lowest overall average difference, are most conservative in the presence of dust, and have the lowest positive bias for clean snow. This is not unexpected, as both quantify the direct radiative impact of snow darkening, but we would not expect them to match exactly because they are quantified differently. Notably, $\mathrm{RF}_{\min \mathrm{P} 07}$ only quantifies in the reduction in visible albedo, whereas the method here does not have a wavelength cutoff for the divergence between LAP containing and clean snow albedo, which does extend in the NIR at higher concentrations as noted in section 3c. This would lead to positive bias for the radiative transfer approach relative to $\mathrm{RF}_{\min \mathrm{P0} 7}$, but this would be offset by the negative bias that would arise from the lower set value for clean snow visible albedo $\left(\mathrm{RF}_{\operatorname{minP} \mathrm{P} 7} ; 0.92\right)$ relative to that from radiative transfer modeling (SNICAR; 0.97-0.98, see section 3a).

The reported semiempirical RF values are most well matched to the physically based values across the ablation season in terms of the root-mean-square difference. Given the consistent relationship found here, Painter method RF could be bias corrected to account for these differences in the future. Overall, the Painter method is robust and this is an important result given, 1) the degree of dissemination of the semiempirical dust in snow RF values (Deems et al. 2013; Painter et al. 2012a, 2018, 2010; Skiles and Painter 2016; Skiles et al. 2012, 2015), 2) that it is the only continuous LAP RF record of its kind, and 3 ) the record now spans over a decade (water years 2005-2017) with coincident snow and dust in snow observations.

\section{Conclusions}

Here a time series of radiative forcing by dust and $\mathrm{BC}$ in snow was simulated directly from snow measurements collected on a near-daily basis in the San Juan Mountains, Colorado. The high temporal, spectral, and vertical resolution dataset allowed us to account for the impact of dust and grain size stratigraphy on RF over a full spring season. Together with the consistent record of snow energy balance fluxes at SBBSA, it is the most complete set of coincident radiation and microphysical snow observations of which we are aware.

Dust dominated both impurity mass and absorption, with instantaneous $\mathrm{RF}$ ranging from 0.25 to $525 \mathrm{~W} \mathrm{~m}^{-2}$, and daily (day time) average $\mathrm{RF}_{D+\mathrm{BC}}$ ranging from 9 to $347 \mathrm{~W} \mathrm{~m}^{-2}$. There was only a minor increase in daily average $\mathrm{RF}$ from $\mathrm{RF}_{D}$ to $\mathrm{RF}_{D+\mathrm{BC}}$, at maximum $\sim 5 \mathrm{~W} \mathrm{~m}^{-2}$. The difference between $\mathrm{RF}_{D}$ and $\mathrm{RF}_{D+\mathrm{BC}}$, the portion accounted for by $\mathrm{BC}$ alone, was about half of $\mathrm{RF}_{\mathrm{BC}}\left(1-7 \mathrm{~W} \mathrm{~m}^{-2}\right)$, indicating absorption by LAPs is reduced in the presence of multiple constituents. Hourly RF values typically fell within or below the range of RF estimated by the Painter method, with an average difference of $+5 \mathrm{Wm}^{-2}$ from direct $\mathrm{RF}\left(\mathrm{RF}_{\operatorname{minP07}}\right)$ and $-8 \mathrm{~W} \mathrm{~m}^{-2}$ from reported $\mathrm{RF}$ (average of $\mathrm{RF}_{\mathrm{minP} 07}$ and $\mathrm{RF}_{\max \mathrm{P07}}$ ).

As mentioned above the RF values presented here only represent the direct radiative impact of snow surface darkening by LAP, but we also recognize that the additional energy from RF heats the snow surface and indirectly enhances grain growth, thereby reducing reflectance over the full portion of the solar spectrum. This albedo reduction enhances snowmelt and exposes the darker underlying ground earlier, a process known as the snow albedo feedback. The indirect impact is a nontrivial contribution to this process, but it can be difficult to disentangle from other factors that enhance snow grain growth, like warming air temperatures. Studies are beginning to address this remaining uncertainty with advanced modeling approaches, and recent results indicate that the reduction in NIR albedo associated with enhanced grain growth accounts for $15 \%-20 \%$ of total radiative forcing by LAP (Skiles 2014; Tuzet et al. 2017).

Absorption by LAPs occurs mainly in the VIS, but direct RF also expands into the NIR as dust concentrations increase and the wavelength of divergence occurs at longer wavelengths. This relationship between dust concentrations and VIS/NIR albedo is important, as it may allow for the estimation of dust content from surface albedo when measurements of snow properties and dust concentrations cannot be made, such as snow albedo inferred from radiance measurements by remote imaging spectroscopy platforms, like NASA's Airborne Snow Observatory (Painter et al. 2016). In this case, clean snow albedo would be modeled from retrieved grain size in each pixel, and then the difference in albedo and the wavelength of divergence could be compared to a lookup table populated with albedo for known impurity concentrations.

With the coming imaging spectrometer mission designated in the National Academies 2017 Earth Science Decadal Survey (National Academies of Sciences, Engineering, and Medicine 2018), in situ measurements will be needed for validation of snow albedo and RF retrievals across the globe. Likewise, NASA has just funded the Earth Venture Instrument mission Earth Surface Mineral Dust Source Investigation (EMIT), which will likewise use visible shortwave infrared (VSWIR) imaging spectroscopy to investigate from the International Space Station the dust cycle globally and its optical properties with constraint of general circulation modeling and mesoscale snowmelt modeling. These missions require in situ 
measurements to validate their retrievals. The validation of the RF inferences from Painter et al. (2007b) at the detailed radiation and energy balance towers described here enables the expansion of these in situ measurements around mountains of the globe. The GEWEX International Network for Alpine Research Catchment Hydrology (Pomeroy et al. 2015) can include these towers to act as a force multiplier on the utilization of the remotely sensed measurements around the globe.

Acknowledgments. This work was funded by the NASA project NNX10AO97G. Part of this work was performed at the Jet Propulsion Laboratory, California Institute of Technology, under a contract with NASA. We appreciate the feedback of two anonymous reviewers, which improved the manuscript.

\section{REFERENCES}

Adolph, A. C., M. R. Albert, J. Lazarcik, J. E. Dibb, J. M. Amante, and A. Price, 2017: Dominance of grain size impacts on seasonal snow albedo at open sites in New Hampshire. J. Geophys. Res. Atmos., 122, 121-139, https://doi.org/10.1002/2016JD025362.

Bond, T. C., and R. W. Bergstrom, 2006: Light absorption by carbonaceous particles: An investigative review. Aerosol Sci. Technol., 40, 27-67, https://doi.org/10.1080/02786820500421521.

— the climate system: A scientific assessment. J. Geophys. Res. Atmos., 118, 5380-5552, https://doi.org/10.1002/jgrd.50171.

Bryant, A., T. H. Painter, J. Deems, and S. M. Bender, 2013: Impact of dust radiative forcing in snow on accuracy of operational runoff prediction in the upper Colorado River basin. Geophys. Res. Lett., 40, 3945-3949, https://doi.org/10.1002/grl.50773.

Deems, J., T. H. Painter, J. Barsugli, J. Belnap, and B. Udall, 2013: Combined impacts of current and future dust deposition and regional warming on Colorado River basin snow dynamics and hydrology. Hydrol. Earth Syst. Sci., 17, 4401-4413, https:// doi.org/10.5194/hess-17-4401-2013.

Delaney, I., S. Kaspari, and M. Jenkins, 2015: Black carbon concentrations in snow at Tronsen Meadow in Central Washington from 2012 to 2013: Temporal and spatial variations and the role of local forest fire activity. J. Geophys. Res. Atmos., 120, 9160-9172, https://doi.org/10.1002/2015JD023762.

Doherty, S. J., C. Dang, D. A. Hegg, R. Zhang, and S. G. Warren, 2014: Black carbon and other light-absorbing particles in snow of central North America. J. Geophys. Res. Atmos., 119, 12 807-12 831, https://doi.org/10.1002/2014JD022350.

—, D. A. Hegg, J. E. Johnson, P. K. Quinn, J. P. Schwarz, C. Dang, and S. G. Warren, 2016: Causes of variability in light absorption by particles in snow at sites in Idaho and Utah. J. Geophys. Res. Atmos., 121, 4751-4768, https://doi.org/ 10.1002/2015JD024375.

Flanner, M. G., and C. Zender, 2005: Snowpack radiative heating: Influence on the Tibetan Plateau climate. Geophys. Res. Lett., 32, L06501, https://doi.org/10.1029/2004GL022076.

— evolution. J. Geophys. Res., 111, D12208, https://doi.org/ 10.1029/2005JD006834.

— C. S. Zender, J. T. Randerson, and P. J. Rasch, 2007: Presentday climate forcing and response from black carbon in snow.
J. Geophys. Res., 112, D11202, https://doi.org/10.1029/ 2006JD008003.

— — - P. G. Hess, N. M. Mahowald, T. H. Painter, V. Ramanathan, and P. J. Rasch, 2009: Springtime warming and reduced snow cover from carbonaceous particles. Atmos. Chem. Phys., 9, 2481-2497, https://doi.org/10.5194/acp-9-2481-2009.

Grams, G. W., I. H. Blifford, D. Gillette, and P. B. Russell, 1974: Complex index of refraction of airborne soil particles. J. Appl. Meteor., 13, 459-471, https://doi.org/10.1175/15200450(1974)013<0459:CIOROA > 2.0.CO;2.

Hadley, O., C. Corrigan, T. Kirchstetter, S. Cliff, and V. Ramanathan, 2010: Measured black carbon deposition on the Sierra Nevada snow pack and implication for snow pack retreat. Atmos. Chem. Phys., 10, 7505-7513, https://doi.org/10.5194/acp-10-7505-2010.

Kaspari, S., T. H. Painter, M. Gysel, S. M. Skiles, and M. Schwikowski, 2014: Seasonal and elevational variations of black carbon and dust in snow and ice in the Solu-Khombu, Nepal and estimated radiative forcings. Atmos. Chem. Phys., 14, 8089-8103, https://doi.org/10.5194/acp-14-8089-2014.

_ , S. M. Skiles, I. Delaney, D. Dixon, and T. H. Painter, 2015: Accelerated glacier melt on Snow Dome, Mt. Olympus, Washington, USA, due to deposition of black carbon and mineral dust from wildfire. J. Geophys. Res. Atmos., 120, 2793-2807, https:// doi.org/10.1002/2014JD022676.

Landry, C., K. Buck, M. S. Raleigh, and M. P. Clark, 2014: Mountain system monitoring at Senator Beck Basin, San Juan Mountains, Colorado: A new integrative data source to develop and evaluate models of snow and hydrologic processes. Water Resour. Res., 50, 1773-1788, https://doi.org/10.1002/2013WR013711.

Libois, Q., G. Picard, J. France, L. Arnaud, M. Dumont, C. Carmagnola, and M. King, 2013: Influence of grain shape on light penetration in snow. Cryosphere, 7, 1803, https://doi.org/ 10.5194/tc-7-1803-2013.

Matt, F. N., and J. F. Burkhart, 2018: Assessing satellite derived radiative forcing from snow impurities through inverse hydrologic modelling. Geophys. Res. Lett., 45, 3531-3541, https:// doi.org/10.1002/2018GL077133.

- — , and J.-P. Pietikäinen, 2018: Modelling hydrologic impacts of light absorbing aerosol deposition on snow at the catchment scale. Hydrol. Earth Syst. Sci., 22, 179-201, https:// doi.org/10.5194/hess-22-179-2018.

Munson, S. M., J. Belnap, and G. S. Okin, 2011: Responses of wind erosion to climate-induced vegetation changes on the Colorado Plateau. Proc. Natl. Acad. Sci. USA, 108, 3854-3859, https://doi.org/10.1073/pnas.1014947108.

National Academies of Sciences, Engineering, and Medicine, 2018: Thriving on Our Changing Planet: A Decadal Strategy for Earth Observation from Space. National Academies Press, 700 pp., https://doi.org/10.17226/24938.

Neff, J. C., and Coauthors, 2008: Increasing eolian dust deposition in the western United States linked to human activity. Nat. Geosci., 1, 189-195, https://doi.org/10.1038/ngeo133.

Nolin, A. W., and J. Dozier, 2000: A hyperspectral method for remotely sensing the grain size of snow. Remote Sens. Environ., 74, 207-216, https://doi.org/10.1016/S0034-4257(00)00111-5.

Oaida, C. M., Y. Xue, M. G. Flanner, S. M. Skiles, F. De Sales, and T. H. Painter, 2015: Improving snow albedo processes in WRF/SSiB regional climate model to assess impact of dust and black carbon in snow on surface energy balance and hydrology over western US. J. Geophys. Res. Atmos., 120, 3228-3248, https://doi.org/10.1002/2014JD022444.

Painter, T. H., N. P. Molotch, M. P. Cassidy, M. G. Flanner, and K. Steffen, 2007a: Contact spectroscopy for determination of 
stratigraphy of snow optical grain size. J. Glaciol., 53, 121-127, https://doi.org/10.3189/172756507781833947.

— , A. P. Barrett, C. C. Landry, J. C. Neff, M. P. Cassidy, C. R. Lawrence, K. E. McBride, and G. L. Farmer, 2007b: Impact of disturbed desert soils on duration of mountain snow cover. Geophys. Res. Lett., 34, L12502, https://doi.org/ 10.1029/2007GL030284.

_ J. S. Deems, J. Belnap, A. F. Hamlet, C. C. Landry, and B. Udall, 2010: Response of Colorado River runoff to dust radiative forcing in snow. Proc. Natl. Acad. Sci. USA, 107, 17 125-17 130, https://doi.org/10.1073/pnas.0913139107.

_- A. Bryant, and S. M. Skiles, 2012a: Radiative forcing by light absorbing impurities in snow from MODIS surface reflectance data. Geophys. Res. Lett., 39, L17502, https://doi.org/10.1029/ 2012 GL052457.

— S. M. Skiles, J. Deems, A. Bryant, and C. Landry, 2012b: Dust radiative forcing in snow of the Upper Colorado River Basin: Part 1. A 6 year record of energy balance, radiation, and dust concentrations. Water Resour. Res., 48, W07521, https://doi.org/ 10.1029/2012WR011985.

— sion of scanning lidar, imaging spectrometer, and physicallybased modeling for mapping snow water equivalent and snow albedo. Remote Sens. Environ., 184, 139-152, https://doi.org/ 10.1016/j.rse.2016.06.018.

— , S. M. Skiles, J. S. Deems, T. W. Brandt, and J. Dozier, 2018: Variation in rising limb of Colorado River snowmelt runoff hydrograph controlled by dust radiative forcing in snow. Geophys. Res. Lett., 45, 797-808, https://doi.org/10.1002/2017GL075826.

Pomeroy, J., M. Bernhardt, and D. Marks, 2015: Water resources: Research network to track alpine water. Nature, 521, 32, https://doi.org/10.1038/521032c.

Qian, Y., and Coauthors, 2015: Light-absorbing particles in snow and ice: Measurement and modeling of climatic and hydrologic impact. Adv. Atmos. Sci., 32, 64-91,https://doi.org/ 10.1007/s00376-014-0010-0.

Ricchiazzi, P., S. R. Yang, C. Gautier, and D. Sowle, 1998: SBDART: A research and teaching software tool for planeparallel radiative transfer in the Earth's atmosphere. Bull. Amer. Meteor. Soc., 79, 2101-2114, https://doi.org/10.1175/ 1520-0477(1998)079<2101:SARATS $>2.0 . C O ; 2$.

Schwarz, J. P., S. J. Doherty, F. Li, S. T. Ruggiero, C. E. Tanner, A. E. Perring, R. S. Gao, and D. W. Fahey, 2012: Assessing Single Particle Soot Photometer and Integrating Sphere/ Integrating Sandwich Spectrophotometer measurement techniques for quantifying black carbon concentration in snow Atmos. Meas. Tech., 5, 2581-2592, https://doi.org/10.5194/ amt-5-2581-2012.

Skiles, S. M., 2014: Dust and black carbon radiative forcing controls on snowmelt in the Colorado River basin. Ph.D. dissertation, University of California, Los Angeles, 251 pp., https://escholarship.org/uc/item/27s9r0j9.

_ , and T. H. Painter, 2016: A 9-yr record of dust on snow in the Colorado River Basin. Proceedings of the 12th Biennial
Conference of Science and Management on the Colorado Plateau, USGS Scientific Investigations Rep. 2015-5180, 3-12, https://pubs.usgs.gov/sir/2015/5180/sir20155180.pdf.

_, and - 2017: Daily evolution in dust and black carbon content, snow grain size, and snow albedo during snowmelt, Rocky Mountains, Colorado. J. Glaciol., 63, 118-132, https:// doi.org/10.1017/jog.2016.125.

, - _ J. Deems, C. Landry, and A. Bryant, 2012: Dust radiative forcing in snow of the Upper Colorado River Basin: 2. Interannual variability in radiative forcing and snowmelt rates. Water Resour. Res., 48, W07522, https://doi.org/10.1029/ 2012WR011986.

— _ - J. Belnap, L. Holland, R. Reynolds, H. L. Goldstein, and J. C. Lin, 2015: Regional variability in dust on snow processes and impacts in the upper Colorado River Basin. Hydrol. Processes, 29, 5397-5413, https://doi.org/10.1002/hyp.10569.

,$- \ldots$, and G. S. Okin, 2017: A method to retrieve the spectral complex refractive index and single scattering optical properties of dust deposited in mountain snow. J. Glaciol., 63, 133147, https://doi.org/10.1017/jog.2016.126.

Stamnes, K., S.-C. Tsay, W. J. Wiscombe, and K. Jayaweera, 1988: Numerically stable algorithm for discrete-ordinate-method radiative transfer in multiple scattering and emitting layered media. Appl. Opt., 27, 2502-2509, https://doi.org/10.1364/ AO.27.002502.

Sterle, K. M., J. R. McConnell, J. Dozier, R. Edwards, and M. Flanner, 2013: Retention and radiative forcing of black carbon in the Eastern Sierra Nevada snow. Cryosphere, 7, 365374, https://doi.org/10.5194/tc-7-365-2013.

Toon, O. B., C. P. McKay, T. P. Ackerman, and K. Santhanam, 1989: Rapid calculation of radiative heating rates and photodissociation rates in inhomogeneous multiple scattering atmospheres. J. Geophys. Res., 94, 16287-16301, https://doi.org/ 10.1029/JD094iD13p16287.

Tuzet, F., and Coauthors, 2017: A multilayer physically based snowpack model simulating direct and indirect radiative impacts of light-absorbing impurities in snow. Cryosphere, 11, 2633-2653, https://doi.org/10.5194/tc-11-2633-2017.

Warren, S. G., 1982: Optical properties of snow. Rev. Geophys. Space Phys., 20, 67-89, https://doi.org/10.1029/RG020i001p00067.

— , and R. E. Brandt, 2008: Optical constants of ice from the ultraviolet to microwave: A revised compilation. J. Geophys. Res., 113, D14220, https://doi.org/10.1029/2007JD009744.

Wendl, I. A., J. A. Menking, R. Färber, M. Gysel, S. Kaspari, M. J. G. Laborde, and M. Schwikowski, 2014: Optimized method for black carbon analysis in ice and snow using the Single Particle Soot Photometer. Atmos. Meas. Tech., 7, 2667 2681, https://doi.org/10.5194/amt-7-2667-2014.

Zhao, C., and Coauthors, 2014: Simulating black carbon and dust and their radiative forcing in seasonal snow: A case study over North China with field campaign measurements. Atmos. Chem. Phys., 14, 11 475-11491, https://doi.org/ 10.5194/acp-14-11475-2014. 